\title{
Effects of Honey on Stress-Induced Ulcers in Rats
}

\author{
AONAN A. AL-MAZROOA, DA, FRCSI* and MANSOUR I. SULAIMAN, PhD** \\ Department of Anaesthesia* and Department of Pharmacology":", \\ Faculty of Medicine \& Allied Sciences, King Abdulaziz \\ University, Jeddah, Saudi Arabia
}

\begin{abstract}
The effects of honey on stress-induced ulcers were examined in rats. Stress was induced by using the Strain and Water Immersion technique (6 hours). Ulcer incidence and severity were quantified by an ulcer index.A honey solution, which consisted of $40 \%$ honey in water, was administered orally in dose volumes of 1,3,5,7 and $14 \mathrm{ml} / \mathrm{kg}, 20 \mathrm{~min}$ before stress induction in 48 hr-fasting rats. Control rats received equivalent volumes of a Honey Control Solution (HCS). The systemic effects of honey on stress induced ulcers were examined by intraperitoneal injection of honey $(3.5 \mathrm{ml} / \mathrm{kg}) 10 \mathrm{~min}$. before stress induction. The effect of a honey solution on gastro-intestinal tract motility was examined by using a charcoal meal incorporated with honey or HCS. Results show that intraluminal honey administration lowers the incidence of stress-induced ulcers by $150 / 0$ relative to that of control rats who received saline $\left(\mathrm{X}^{2}=3.1, \mathrm{P}=.07\right)$. Rats pretreated with a honey solution $(3,5,7$ and 14 $\mathrm{rnl} / \mathrm{kg}$ ) showed a significantly lower ulcer index than HCS-pretreated rats $(\mathrm{P}<$ .05). Incorporation of honey into a charcoal meal lowers OJ.T. stress-induced hypermotility by $37.80 / 0$ of matched control received saline incorporated charcoal meal. It was concluded that intraluminal administration of honey decreases the severity of stress-induced ulcersin rats.
\end{abstract}

Keywords: Honey, Stress, Pepticulcer, Gastrointestinal motility.

\section{Introduction}

The incidence of upper gastrointestinal bleeding due to stress-induced ulcers is estimated at 5-25\% depending on the criteria[1]. The exact causes for stress-induced ulcers are poorly understood. Several theories were suggested to explain the etiology of stressinduced ulcers in Intensive Care Unit (ICU) patients. These include: inadequate blood flow to the gastric mucosa, nutritional impairment, and an excessive increase in gastric acid secretion.

Correspondence \& reprint requests to: Dr. Mansour I. Sulaiman, P.O. Box 11047, Jeddah 21453, Saudi Arabia. Acceptedfor publication: 21 March 1998. Received: 30 September 1997. 
Prophylactic therapy with $\mathrm{H}_{2 \text {-antagonist }}$ or antacids has little or no effect on the incidence of mucosal lesions seen soon after admission to the ICU[2-4J. Also, $\mathrm{H}_{2}$ antagonist, antacid, and sucralfate could complicate the clinical condition with serious side effects[5-8]. For some time, honey was implicated as a therapy for peptic ulcers in folk medicine. Scientifically, honey was reported for its ability to enhance the healing of topical wounds[2,4,9]. Recently, Abu et al/lO found that honey prevents indomethacininduced ulcers and decreases the severity of alcohol-induced ulcers in rats[3]. However, it is unknown whether honey has a prophylactic effect against stress-induced ulcers. Therefore, the aim of the present work is to examine the effects of honey on stressinduced ulcers in rats.

\section{Materials and Methods}

Animals: Male Wistar rats (150-190 g) supplied by the Animal Unit at King Fahad Medical Research Centre, Faculty of Medicine \& Allied Sciences, King Abdulaziz University, were used in this work. Rats were housed in groups of five. Rats were under controlled conditions at a temperature of $32^{\circ} \mathrm{C}$ and a lighting cycle $(12+12 \mathrm{hr}$.) of 18.00-6.00 hr. dark and 6.00-18.00 hr. light. Rats were given standard food and water. Food was withheld for $48 \mathrm{hr}$. before stress induction, during which time they were maintained on a drinking solution consisting of $8 \%(\mathrm{v} / \mathrm{v})$ sucrose in saline. The solution was removed one hr. before the experiment. During fasting, rats were kept in starvation cages with a raised, wide-wire mesh floors to prevent coprophagy.

Materials: Pure, unboiled, commercial honey (known as cider honey) was used in these experiments. Authenticity of honey was tested in this lab; it showed a dextrose: fructose ratio of 0.94 . Honey was diluted with distilled water $(1: 3 \mathrm{v} / \mathrm{v})$. A solution consisting of glucose, fructose, sucrose, and maltose $(31,38,1.3$ and $7.3 \mathrm{~g} \%$, respectively) was used as the $\mathrm{HCSl}^{\mathrm{IO}}$.

Stress induction: The 48-hr. fasting rats were placed individually into close-fitting, tubular, perplex cages after which they were immersed in water at $19^{\circ} \mathrm{C}^{[6]}$. After 6 hours the animals were killed by a firm blow to the head and their stomach was dissected, opened along their greater curvature, and gently rinsed under running water. Gastric mucosal damage was measured under a dissecting microscope. The following scoring system[5] was used to grade the incidence and severity of the lesions: (i) shedding epithelium $=10$, (ii) petechial and frank hemorrhage $=20$, (iii) one or two ulcers $=30$, (iv) many ulcers $=40$, and (v) perforated ulcers $=50$.

Experiment protocol: Fasting animals (48 hr.) were allocated at random to four groups of 16 rats each. A honey solution in dose volumes of 1,3.5, 7 and $14 \mathrm{ml} / \mathrm{kg}$ was administered orally to rats in groups 1,2, 3, and 4, respectively, $20 \mathrm{~min}$ before stress induction. Matched control rats received equivalent volumes of the HCS. The systemic effects of honey on stress-induced ulcers were examined by injection of a honey solution ( $3.5 \mathrm{ml} / \mathrm{kg}$ intraperitoneally (IP», into the 48-hr-fasting rats $(\mathrm{n}=7) 10 \mathrm{~min}$ before stress induction. Control rats received equivalent volumes of $\operatorname{HCS}(n=5)$ or saline $(n=4)$.

Gastrointestinal tract motility: GIT motility was determined by the use of an oral charcoal meal as a marker. The charcoal meal consisted of one part charcoal, two parts 
plain white flour, and six parts saline. To determine the GIT motility in unstressed rats, 48 -hr fasting rats $(\mathrm{n}=\mathrm{LO})$, were given a charcoal meal $(2 \mathrm{mUrat})$ and left aside in their original cages for $25 \mathrm{~min}$. Immediately after, the rats were killed and the distance travelled by the charcoal along the small intestine was determined and expressed as a percentage of total intestinal length. These rats were regarded as the unstressed control group. To determine the effects of honey on G.I.T motility in stressed rats, 48-hr fasting rats were allocated at random to the following oral administration conditions: (i) a honey incorporated charcoal meal in which a honey solution replaced saline in the charcoal meal, (ii) a charcoal meal incorporated with the HCS solution, and (iii) a charcoal meal incorporated with saline $(n=10)$ for each group. Charcoal meals $(2 \mathrm{ml} / \mathrm{rat})$ were given $10 \mathrm{~min}$ before stress induction. Stress was induced in rats by restraints and immersion into water at 19() $\mathrm{C}$ for $25 \mathrm{~min}$, as described above.

Statistical analysis: Results were expressed as mean \pm SD. Differences between the means were examined for statistical significance by the impaired student's r-test, The effect of honey, HCS and saline dose volumes on ulcer index values were examined by the analysis of variance in each group separately. Ulcer incidence was analyzed by chisquare test. A $5 \%$ level of significance was used throughout.

\section{Results}

Effects of honey on stress-induced ulcers: Oral administration of honey solution before stress induction lowers the incidence rate and the ulcer index values in stressed rats. The incidence of gastric mucosal damage in saline-pretreated rats exposed to restraint and water immersion for six hrs was $98.3 \%$. The ulcers, which were linear of focal hemorrhagic in shape, occurred along the gastric mucosal folds. The stress-ulcer incidence among honey- and HCS-pretreated rats were $850 / 0$ and $96.4 \%$ in all groups, respectively.

An analysis of the ulcer incidence by contingency tables showed no significant difference between the honey- and saline-pretreated rats $\left(\mathrm{X}^{2}=3.1, \mathrm{P}=0.07\right)$, nor between the HCS- and saline-pretreated rats. A significant difference was seen between honey and HCS-pretreated rats $\left(X^{2}=5.9, P=0.015\right)$.

A one-way analysis of means of ulcer index values for HCS- and saline-pretreated rats by student's $t$-test showed no significantdifferencebetween the two groups $(\mathrm{P}=.057)$. Analysis of variance in the saline-pretreated rats showed that saline volumes had no significant effect on the ulcer index values $(\mathrm{P}=.06)$. The rats pretreated with HCS $(1-14$ $\mathrm{ml} / \mathrm{kg}$ ) showed lower ulcer index values than that of the saline-pretreated rats. The dose response curve for HCS was shifted downward to that of saline-pretreated rats (Fig. 1).

Analysis of variance in HCS-pretreated rats showed that HCS volumes had no significant effect on the ulcer index values $(\mathrm{P}=.07)$.

Rats pretreated with the honey solution (1-14 mg/kg) showed significantly lower ulcer index values than that of the saline-pretreated rats $(\mathrm{P}<.05)$. Analysis of ulcer index means showed that the honey- and HCS-pretreated rats had no significant differences at 
lower doses ( $\mathrm{I}$ and $3.5 \mathrm{mIl} \mathrm{kg}$ ), yet a statistically significant difference in ulcer index values was observed at higher doses ( 7 and $14 \mathrm{ml} / \mathrm{kg}, \mathrm{P}<0.05$ ). The effects of honey solution on stress-induced ulcers was volume dependent $(\mathrm{r}=-0.90, \mathrm{P}=0.08)$.

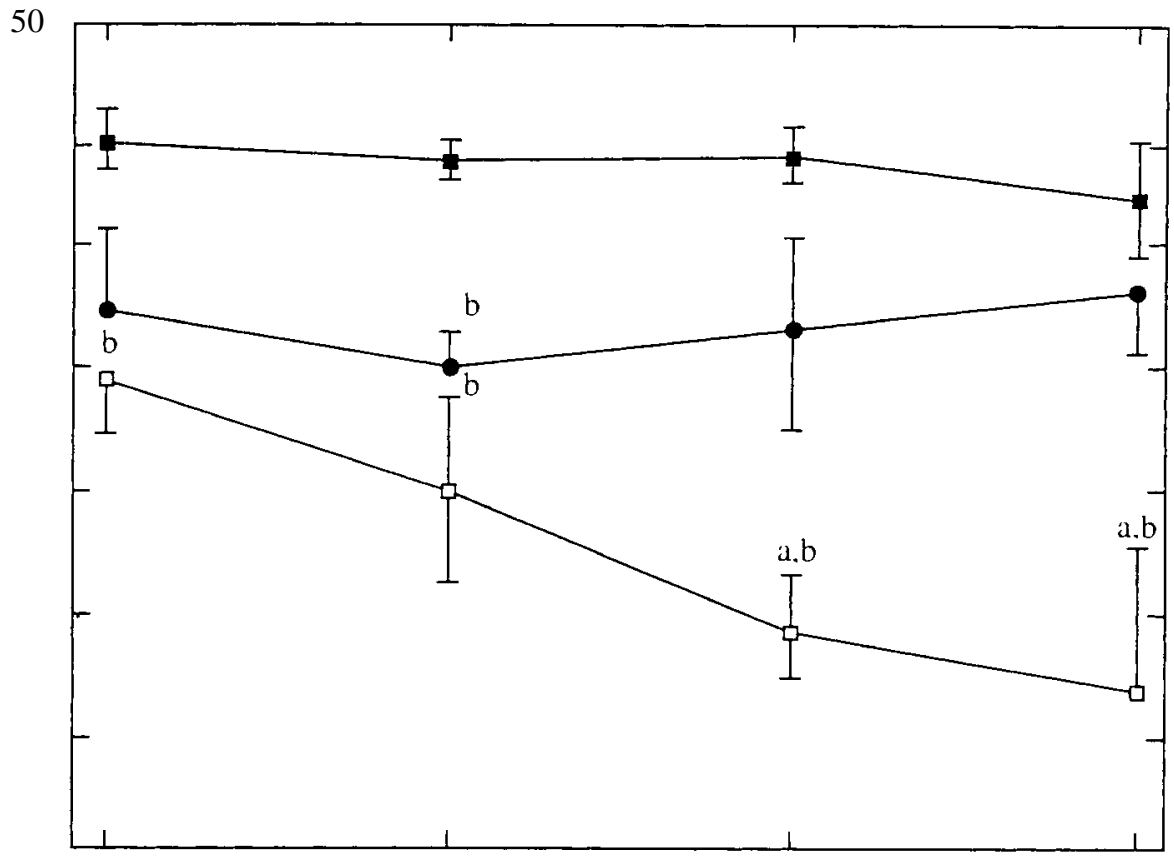

FIG. 1. Effect of oral administration of honey ( 0 ),HCS $(\bullet)$, and saline $(\bullet)$ on the incidence and the severity of stress-induced ulcers (ulcer index) in rats. Results are presented as mean $\pm \mathrm{SO}, \mathrm{n}=16$ for each point (a) suggests significance against saline, (b) indicates significance against the HCSpretreated rats $(\mathrm{P}<0.05)$.

Effects of parenteral honey administration on gastric ulcers: Figure 2 shows that rats injected with honey $(3.5 \mathrm{ml} / \mathrm{kg}$, IP) $10 \mathrm{~min}$ before stress induction.had a significantly higher ulcer index than the corresponding control rats who received HCS or saline (P $<0.05$ ). The ulcer index for honey-, saline-, and HCS-injected rats was $48 \pm 3,38 \pm 4.5$, and $4,5 \pm 3.5 /$ rat, respectively.

Effects of honey on GIT motility in stressed rats: Rats exposed to restraint-waterimmersion stress for 25 min showed a significantly higher GIT motility than the unrestrained rats $(\mathrm{P}<0.05)$. The charcoal meal traveling distance in the restrained rats was $55 \pm 50 / 0$ vs. $45 \pm 2.7 \%$ for the unrestrained rats, respectively. The restrained rats who received the charcoal meal incorporated with a honey solution showed lower GIT motility than the rats who received the charcoal meal incorporated with a saline $(\mathrm{P}<0.05)$ solution, yet slightly higher than that of the rats who received the HCS-incorporated charcoal meal. The charcoal travelling distance for the honey- and HCS-pretreated rats was $34.2 \pm 2.5 \%$ and $24.72 \pm 3.9 \%$, respectively (Fig. 3 ). 


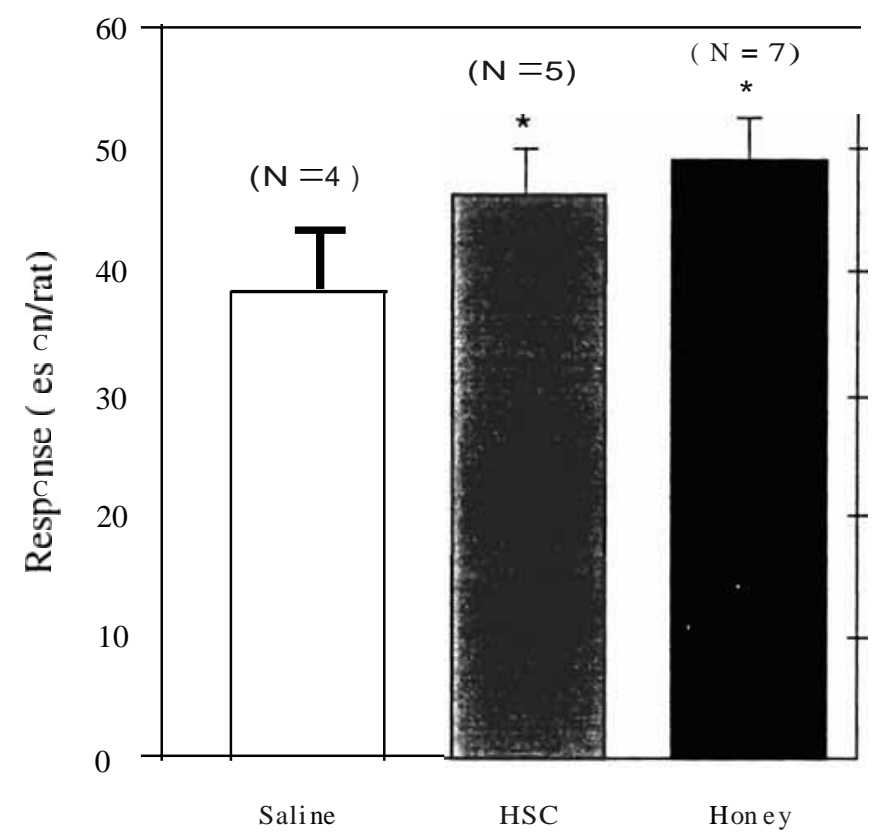

FIG. 2. Effects of intraperitoneal injection of honey and $\mathrm{HCS}(3.5 \mathrm{ml} / \mathrm{kg}) 10 \mathrm{~min}$. before stress induction on stress-induced ulcers in rats. Results are presented as mean $\pm \mathrm{SD}, \mathrm{n}=$ number, $(*)$ indicates significance $(\mathrm{P}<0.05$.

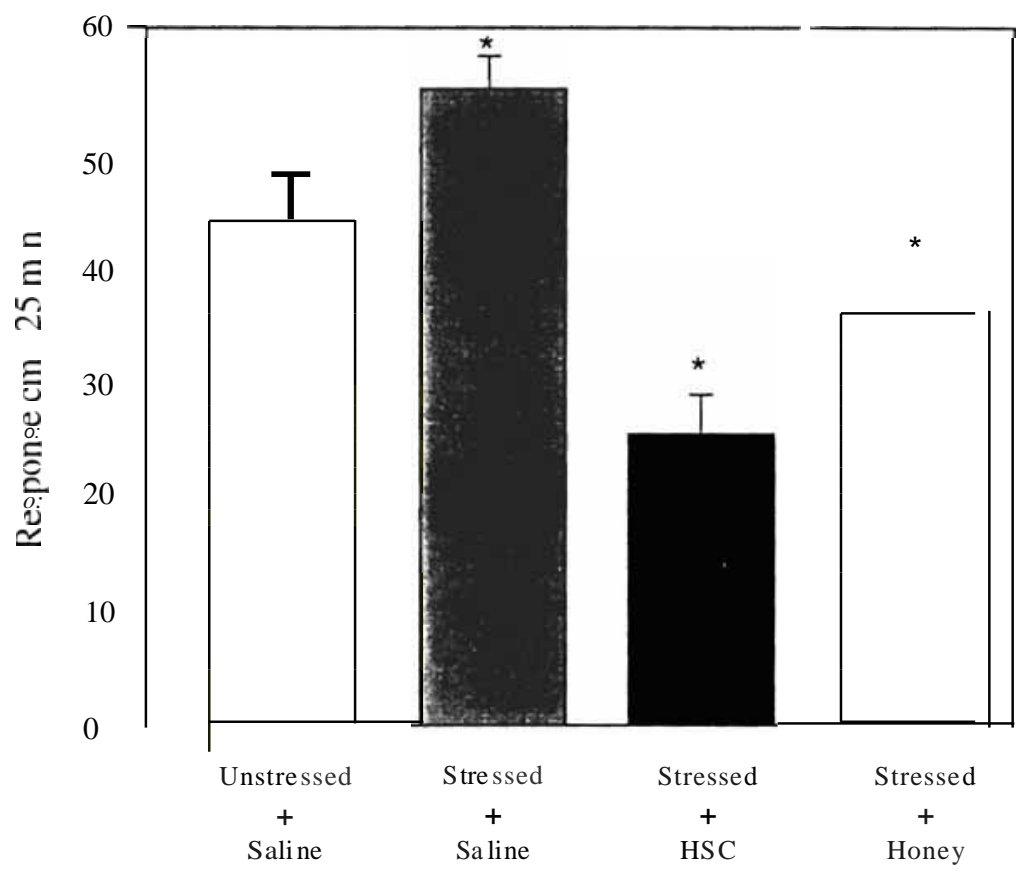

FIG. 3. Effects of honey, saline. and HCS incorporated in the charcoal meal on GfT motility in stressed rats. Results are presented as mean $\pm \mathrm{SD}, \mathrm{n}=10$ for each point, $(*)$ indicates significance $(\mathrm{P}<0.05)$. 


\section{Disc.ussion}

Results presented in this work show that intraluminal administration of honey solution before stress induction decreased the incidence and severity of stress-induced gastric ulcers in rats. The exact mode of action is unknown. the effect could be locally mediated as the systemic administration of honey or HCS increased the severity of stressinduced ulcers. Several workers suggested that acute stress-induced gastric lesions are primarily a result of loss of the protective mechanism of the gastric mucosa[3,4]. In this context, it was speculated that honey may act as a barrier between gastric mucosa and the excessive gastric acid secreted during stress. Conversely, the presence of honey in GIT may stimulate blood flow to the stomach and encounter stress-induced ischemia. For several years honey has been claimed to be a topical anti-ulcerogenic material against several forms of topical ulcers, e.g., burn'11,2], traumatic, diabetic"'", and topical experimental ulcers[41. This anti-ulcerogenic effect of honey was attributed to several features in honey such as high osmolality"'", ability to provide energy[S,121, and antimicrobial[6,11,13-16] properties. Although it is unknown whether any of these mechanisms had a role in the anti-ulcer effects of honey in stressed rats. The high carbohydrate content of honey probably has little or no role to play in its anti-ulcer effects, as the HCS had little effect on stress-induced gastric ulcers. Honey's anti-ulcer effects could be due to factors other than its nutritional properties as it was suggested earlier[1].

The finding described in the present work that parenteral honey and HCS have increased the severity of stress-induced ulcers is intriguing. This may be due to the presence of the hyperosmolar solution in the peritoneal cavity leading to a fluid shift and mesenteric ischemia, which is a major part in mucosal barrier derangernentl'i'.

The effect of honey on GIT in stressed rats apparently is multifactorial, as honey decreased the GIT hypermotility induced by.stress in rats. Stress usually increases GIT motility $[2.12,13,17]$. The underlying mechanism for honey effects on the GIT motility was unknown, but honey is known for its anti-diarrheal effects in gastroenteritis which was attributed to its antimicrobial properties'14]. Honey's effect on GIT motility in stressed rats could be mediated via the stimulation of the sympathetic nervous system because it is generally accepted that a high-carbohydrate diet stimulates the sympathetic nervous system[5,18,19].

Although the anti-ulcer effects of honey were not compared with that of current antiulcer regiments, honey may have some advantages as a potential anti-ulcer medication, e.g., it is cheap, readily available, harmless, nutritiousl'"12], and, most importantly, has antimicrobial effects[11,13-16]. These last effects could be useful in the prevention of bacterial colonization of the gastric juice, small portions of which are regurgitated on a regular basis and are often aspirated even in the presence of endotracheal intubation. This aspiration enhances colonization of the respiratory tract and often leads to an infection, particularly in immunocompromised, critically ill patients[20]. Further experiments are still required to examine and confirm the prophylactic effects of honey in patients susceptible to stress-induced ulcers. 


\section{References}

[I] Geus WP, Lamers CBHW. Prevention of stress ulcer bleeding: a review. Scand J Gastroenterol 1990; 178: $23-41$.

[2] Williams CL, Villar RG, Peterson JM, Burks TF. Stress induced changes in intestinal transit in the rats: a model for irritable bowel syndrome. Gastroenterology 1988; 94: 611-621.

[31 Halloran LG, Zfass AM, Gayle WE, Wheeler CB, Miller JD. Prevention of acute gastrointestinal complications after severe head injury: a controlled trial of cimetidine prophylaxis. Am J Surg 1980; 139: $44-48$

[4] Stannard VA, Farquhar IK, Morris DL. Stress ulceration and gastric function in the critically ill patient's. Dig Dis 1990; 8: 80-88.

[5] Young JB, Saville E, Rothwell NJ, Stock MJ, Landsberg L. Effects of diet and cold exposure on morepinephrine turnover in brown adipose tissue in the rat. J Clin Invest 1982; 69: 1061-1071.

[6] Takagi K, Okabe S. The effects of drugs on the production and recovery process of the stress ulcer. Jpn J Pharmacol 1986; 18: 9-18.

[7] Tryba M. Prevention of stress bleeding with ranitidine or pirenzepine and the risk of pneumonia. J Clin Anaesthesia 1988; 1: 12-20.

[8] Tryba M. Risk of acute stress bleeding and nosocomial pneumonia in ventilated intensive care unit patients: sucralfate versus antacids. Am J Med 1987; 83(3B): 117-124.

[9] Efem SEE. Clinical observations on the wound healing properties of honey. J Surg 1988; 75: 681-683.

[10] Abu TMM, AI-Humayyd MS, Madan BR. Natural honey prevents indomethacin- and ethanol-induced gastric lesions in rats. Saudi Med J 1991; 11: 275-279.

[11] Phillips CEo Honey for burn. Gleamings in Bee Culture 1933; 61: 284-290.

[12] Williams CL, Peterson JM, Villar RG, Burks TF. Corticotropin releasing factor directly mediates colonic responses to stress. Am J Physiol 1987; 253: 582-586.

[13] White JW, Subers MH, Schepartz AI. The identification of inhabitane. The antimicrobial factor in honey as hydrogen peroxidase and its origin in a honey glucose oxidase system. Biochem Biophys Acta 1963; 73: $57-70$.

[] 4] HafTejee IE, Moosa A. Honey in the treatment of infantile gastroenteritis. Br Med J 1985:290: 18661867.

[15] Temnov VA. Bactericidal properties of honey and other bee keeping products for the healing of wounds. Bee World 1944; 25: 7-11.

[16] Khristov G, Mladenov S. Honey in surgical practice: the antibacterial properties of honey. Khirurglia 1961: 14: 945-947.

[17] Gaudin C, Safar M, Cuche JL. Effects of restraint stress on caecholamine concentrations in the glandular stomach of rats. Life Sci 1990; 47: 2003-2008.

[18]' Rappaport EB, Young JB, Landsberg L. Initiation, duration and dissipation of diet-induced changes in sympathetic nervoussystem activity in the rat. Metabolism 1982:31: 143-146.

[19] Levin BE, Triscari J, Sullivan AC. Altered sympathetic activity during development of diet induced obesity in rat. Am J Physiol 1983; 244(3): R347-R355.

[20] Tryba M. Sucralfate versus antacids or H2 antagonist for stress ulcer prophylaxis: a meta analysis on efficacy and pneumonia rate. Crit Care Med 1991; 19: 942-949. 
تأثير العسل على قرحة المعدة الناتجة من الضغط النفسي عند الفئران

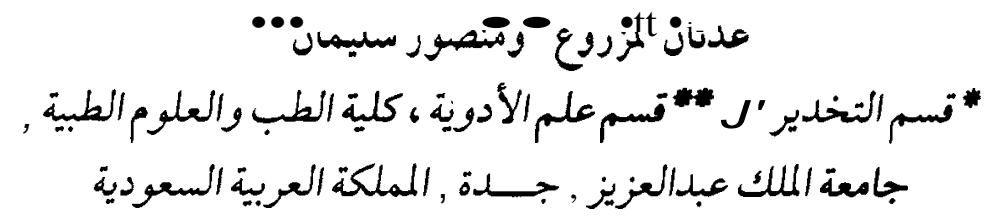

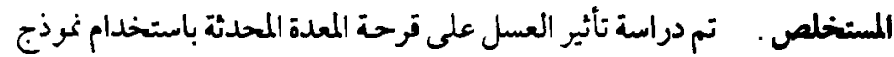

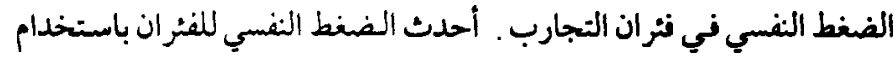

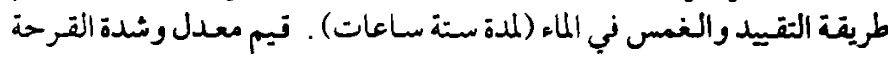

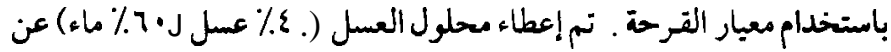

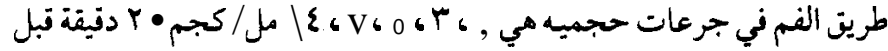

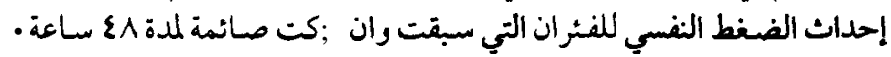

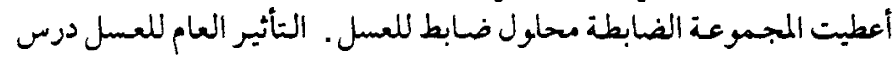

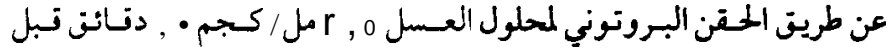

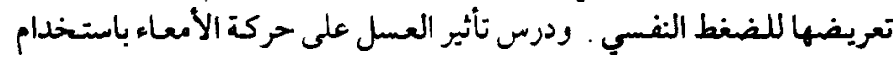

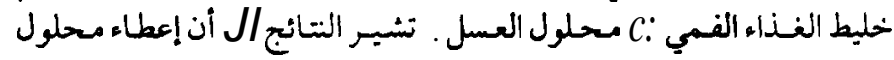

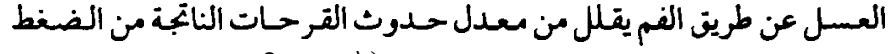

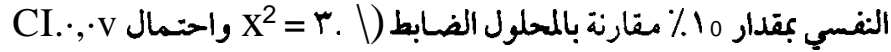
كمالوحظ نقصان يعتد به إحصائيا على مقياس القرحة (احتمال

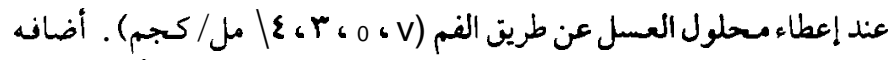

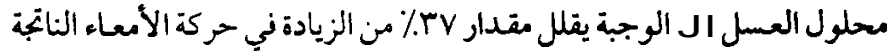

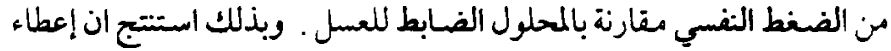

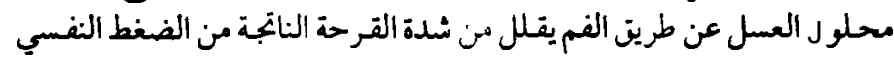

